\title{
Seasonal differences in biochemical parameters of bone remodelling
}

\author{
A S Douglas, M H Miller, D M Reid, J D Hutchison, R W Porter, S P Robins
}

University
Department of
Medicine and
Therapeutics, Medical
School, Aberdeen
A S Douglas
University
Department of
Orthopaedic Surgery
J D Hutchison
R W Porter
Institute of
Biochemistry,
Royal Infirmary,
Glasgow
M H Miller
Department of
Rheumatology, City
Hospital, Aberdeen
D M Reid
Division of
Biochemical Sciences,
Rowett Research
Institute, Aberdeen
S P Robins
Correspondence to:
Professor A S Douglas,
University Department of
Medicine and Therapeutics,
Medical School, Foresterhill,
Aberdeen AB9 $2 Z D$.
Accepted for publication
12 December 1995

Abstract

Aims-To compare bone remodelling parameters in late autumn and early spring in 20 post-menopausal women. Methods-The parameters measured were serum osteocalcin and its apparent degree of carboxylation (measured by hydroxyapatite binding), total and bone specific alkaline phosphatase and urinary bone resorption markers, (pyridinoline and deoxypyridinoline). tions were lower in autumn than in spring but the degree of carboxylation was similar. Total and bone specific alkaline phosphatase activities in serum were higher in autumn than in spring. These results support previous observations. However, notable and previously unreported changes in urinary bone resorption markers were observed. Pyridinoline concentrations were lower and deoxypyridinoline higher in autumn compared with spring. The ratio of pyridinoline:deoxypyridinoline was therefore very different between the seasons.

Conclusions-The results clearly demonstrate that seasonal changes in these variables of bone remodelling must be taken into consideration when designing, reporting or analysing studies of bone metabolism in vivo.

(f Clin Pathol 1996;49:284-289)

Keywords: bone, season, osteocalcin, pyridinium, alkaline phosphatase.
Results-Serum osteocalcin concentra-

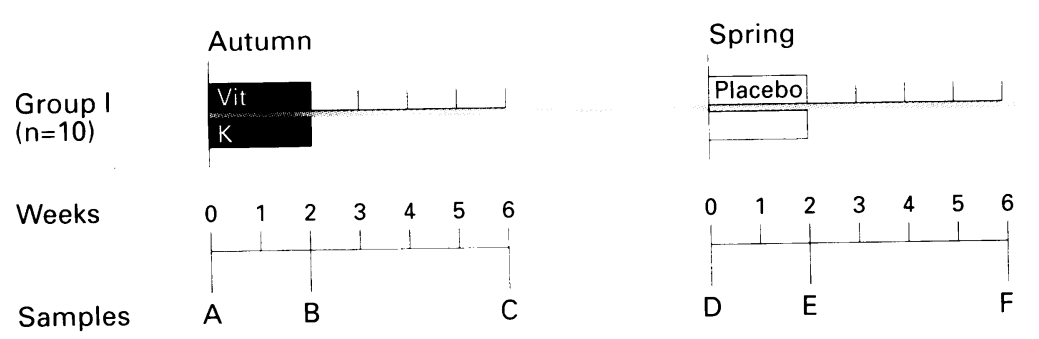

Group II $(n=10)$

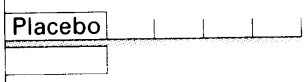

Bone remodelling by formation and resorption is a continuous process. Biochemical parameters are measured to reflect these changes and may be used as indicators of the success or failure of therapeutic regimens. ${ }^{1-3}$ Serum osteocalcin has been widely used as a marker primarily of bone formation ${ }^{4}$ and the pyridinium crosslinks, pyridinoline and deoxypyridinoline have, in recent years, been shown to provide valid indexes of bone resorption. ${ }^{56} \mathrm{~A}$ major consideration in the application of these markers is an appreciation of the physiological variations that occur. A large number of studies have provided information on variations in markers of both bone formation and resorption, relating particularly to diurnal (circadian), day to day and age related effects. $^{7 \cdot 10}$ Generally, little attention has been paid to seasonal changes, although these have been clearly demonstrated for osteocalcin. ${ }^{11}$ The degree of carboxylation of serum osteocalcin can be estimated by hydroxyapatite binding, ${ }^{12-14}$ and statistically significant seasonal variations in the concentrations of undercarboxylated osteocalcin have been noted in elderly women. ${ }^{15}$

The present report provides a detailed analysis of the seasonal changes in serum osteocalcin and its degree of carboxylation, and in urinary pyridinium crosslinks and calcium concentrations. Total and bone specific alkaline phosphatase (ALP) activities were also studied. These results were derived from a study designed to assess the effects of vitamin supplementation in elderly women with osteoporosis, ${ }^{16}$ and gave rise to a total of 60 values for comparisons between spring and autumn.

\section{Methods}

Twenty post-menopausal women who had suffered a Colles fracture at least 18 months previously were enrolled in a study of vitamin supplementation ( $\mathrm{K}$ and $\mathrm{D}$ ). This group of women were osteoporotic in comparison with controls, as determined by bone mineral density (BMD) of the lumbar spine and hip and by measuring attenuation of broad band ultrasound at the os calcis. Figure 1 outlines the study design. The 20 patients (mean age (range) 61.7 (52-73) years) were in two age matched groups I and II. More details are given in an earlier publication. ${ }^{16}$

COLLECTION OF BLOOD AND URINE

Figure 1 Study design. The study started in late November 1991 (autumn) and Figure 1 Study design. The study started in late November 1991 (autumn) and
finished late April 1992 (spring). There was a six week "testing period" at the beginning and end of that time, with about three months "wash out" in between - the discontinuous and end of that time, with about three months "wash out" in between-the discontinuor sampling days $(A-F)$.
Blood $(20 \mathrm{ml})$ was collected by clean venepuncture without haemolysis, the specimen being placed on ice and centrifuged within 90 
minutes of collection. Serum was separated and stored in aliquots at $-20^{\circ} \mathrm{C}$. Sampling was done between 1200 and 1600 hours, each patient having the same appointment time at each of the visits to control for possible circadian changes.

Urine samples were collected in supplied containers on first rising, and kept at $4^{\circ} \mathrm{C}$ until taken to the hospital later that day. The samples were acidified to $\mathrm{pH} 2$ using hydrochloric acid and frozen at $-20^{\circ} \mathrm{C}$ until analysed. The samples were collected on six separate occasions, three $(\mathrm{A}, \mathrm{B}, \mathrm{C})$ in autumn and three $(\mathrm{D}, \mathrm{E}, \mathrm{F})$ in spring. Samples $\mathrm{B}$ and $\mathrm{E}$ were collected two weeks after $A$ and $D$, while $C$ and $F$ were collected four weeks after B and $E$ (fig 1).

Between samples $A$ and $B$, vitamin $K$ supplement was given to half the volunteers (group I) in autumn and to the other half vitamins $K$ and $\mathrm{D}$ were given in the spring (group II). Comparisons were made between samples in autumn and in spring (see later).

The remodelling indexes studied were serum osteocalcin (and its level of apparent carboxylation), urinary pyridinium crosslinks, urinary calcium and creatinine, and serum ALP (total, bone and liver).

\section{MEASUREMENT OF OSTEOCALCIN}

Serum osteocalcin concentrations were measured with the INCSTAR radioimmunoassay kit (IDS Ltd, Boldon, UK), according to the manufacturer's instructions. The intra- and interassay variations were $3-6 \%$ and $5-8 \%$, respectively. In addition, repeated analyses of a standard serum sample stored in aliquots at $-20^{\circ} \mathrm{C}$ showed no significant decrease in the measured osteocalcin concentration over the full time course of the study. Total osteocalcin in serum was measured and an estimate of the degree of carboxylation was obtained by determining the proportion of osteocalcin remaining unbound after mixing the serum with hydroxyapatite (Fluka Chemika, Glossop, UK), as described by Knapen et al. ${ }^{17}$ Thus "bound" refers to the fraction of osteocalcin which binds to hydroxapatite in the laboratory assay, assumed to be fully carboxylated, and "free" refers to the undercarboxylated osteocalcin left in the supernatant fluid after the hydroxyapatite has been centrifuged down.

\section{URINARY PYRIDINIUM CROSSLINKS}

The urine samples were analysed for pyridinoline and deoxypyridinoline using a fully automated method with solid phase extraction and reversed-phase high-performance liquid chromatography, as described by Pratt et al. ${ }^{18}$ With this assay, the overall coefficient of variation was $<3 \%$ for pyridinoline and $<5 \%$ for deoxypyridinoline. Analyses of well characterised standard crosslinks were done with each batch of samples, together with repeated analyses of a standard urine sample stored in aliquots at $-20^{\circ} \mathrm{C}$. These analyses showed that the pyridinoline:deoxypyridinoline ratio did not vary by more than $6 \%$ over the study period.
URINARY CALCIUM AND CREATININE

Both calcium and creatinine were analysed by standard techniques using a Kone autoanalyser.

\section{ALKALINE PHOSPHATASE}

Bone, liver and total ALP activities were measured colorimetrically using a Boehringer Mannheim kit and values were calculated as described previously. ${ }^{18-20}$ Briefly, following measurement of the total ALP activity (a), the assay was repeated in the presence of $0.5 \mathrm{mmol} / 1$ phenylalanine (b), which inhibits ALP activity other than bone and liver, and again after heat inactivation of bone ALP at $56^{\circ} \mathrm{C}$ for 10 minutes (c). Total (a), chemical inhibition (b) and postheat inactivation (c) activities were measured on the same day in such a way that samples A-C or D-F for each patient were measured in the same batch. The values obtained after heat treatment were corrected to account for the proportion of liver enzyme destroyed under these conditions. ${ }^{19}$ The liver ALP is subtracted from the total activity. Measurement of bone plus liver activity by phenylalanine inhibition (b) was used to confirm that no individual patient had a large $(>10 \%)$ contribution from the intestinal or placental isoenzymes. These were all post-menopausal women in whom no placental contribution was expected, but there could have been an intestinal or unexpected tumour source. Animal serum samples were run with each batch of reagent as quality control. For women between the ages of 50 and 70 years the measuring laboratory uses a reference interval of 110-380 U/1 for total ALP activity. No patient had an activity above the upper limit of this range.

In the examination of serum osteocalcin and urinary pyridinium crosslinks there were 60 samples (samples A, B, C) from 20 patients in autumn and 60 samples (D, E, F) in spring. The ALP estimates were made at the end of the study and only 48 samples (16 patients) were available for analysis. In the remaining four patients at least one of the six samples (A-F) had been used up in the previous assays. This explains why in table 3 there are 48,16 and eight pairs rather than the $60,20,10$ pairs in the preceding tables.

\section{EXAMINATION OF RESULTS}

All sets of data were normally distributed and a paired $t$ test was used in comparisons between autumn and spring values in the same individuals.

Because the samples were taken from patients also involved in a trial of vitamin supplementation the data had to be examined not only as a whole (60 samples in autumn and 60 in spring) but also in other smaller groups. There were 20 samples in autumn before the study started to be compared with 20 in spring following the winter "wash out" period and before vitamin supplementation restarted. In view of the remote possibility that the "wash out" was incomplete, comparison was made of 10 samples (A) in autumn from the placebo group II with samples $\mathrm{D}$, the same group ex- 
Table 1 Osteocalcin and percentage carboxylation

\begin{tabular}{|c|c|c|c|c|c|c|c|}
\hline & Assessment* & Autumn & $S D$ & Spring & $S D$ & Paired t test & $p$ value \\
\hline \multicolumn{8}{|c|}{ Osteocalcin (ng/nl) } \\
\hline (60 pairs) & (i) & $2 \cdot 91$ & $1 \cdot 28$ & $3 \cdot 91$ & $1 \cdot 20$ & $t=4 \cdot 71$ & $\mathrm{p}<0.001$ \\
\hline (20 pairs) & (ii) & $2 \cdot 80$ & $1 \cdot 15$ & $3 \cdot 73$ & $1 \cdot 10$ & $t=2.56$ & $p<0.05$ \\
\hline (10 pairs) & (iii) & $2 \cdot 83$ & $1 \cdot 14$ & $3 \cdot 79$ & $1 \cdot 13$ & $t=1.53$ & NS \\
\hline \multicolumn{8}{|c|}{ Percentage carboxylation } \\
\hline (60 pairs) & (i) & $58 \cdot 79$ & $16 \cdot 28$ & $59 \cdot 10$ & $16 \cdot 12$ & $\mathrm{t}=0 \cdot 11$ & NS \\
\hline (20 pairs) & (ii) & $54 \cdot 10$ & $15 \cdot 15$ & $57 \cdot 90$ & $13 \cdot 80$ & $t=0.89$ & NS \\
\hline (10 pairs) & (iii) & $52 \cdot 22$ & $14 \cdot 12$ & $60 \cdot 20$ & $14 \cdot 78$ & $t=1 \cdot 14$ & NS \\
\hline
\end{tabular}

* See Methods.

amined in the spring (fig 1). In the description of results for osteocalcin and pyridinium crosslinks there are three assessments: assessment (i): 60 pairs comparison $(\mathrm{A}+\mathrm{B}+\mathrm{C}$ cf $\mathrm{D}+$ $\mathrm{E}+\mathrm{F}$ ); assessment (ii): 20 pairs comparison (A cf D); assessment (iii): 10 pairs comparison (A (group II) cf D (group II)).

\section{TIMINGS OF THE COLLECTIONS}

The first sample (A) was collected on 25 November 1991 and the last $(F)$ on 28 April 1992. $\mathrm{A}, \mathrm{B}$ and $\mathrm{C}$ were collected over six weeks at the beginning and $\mathrm{D}, \mathrm{E}$ and $\mathrm{F}$ similarly at the end. There was no sampling for 10 weeks in the middle. Samples A and D were about 16

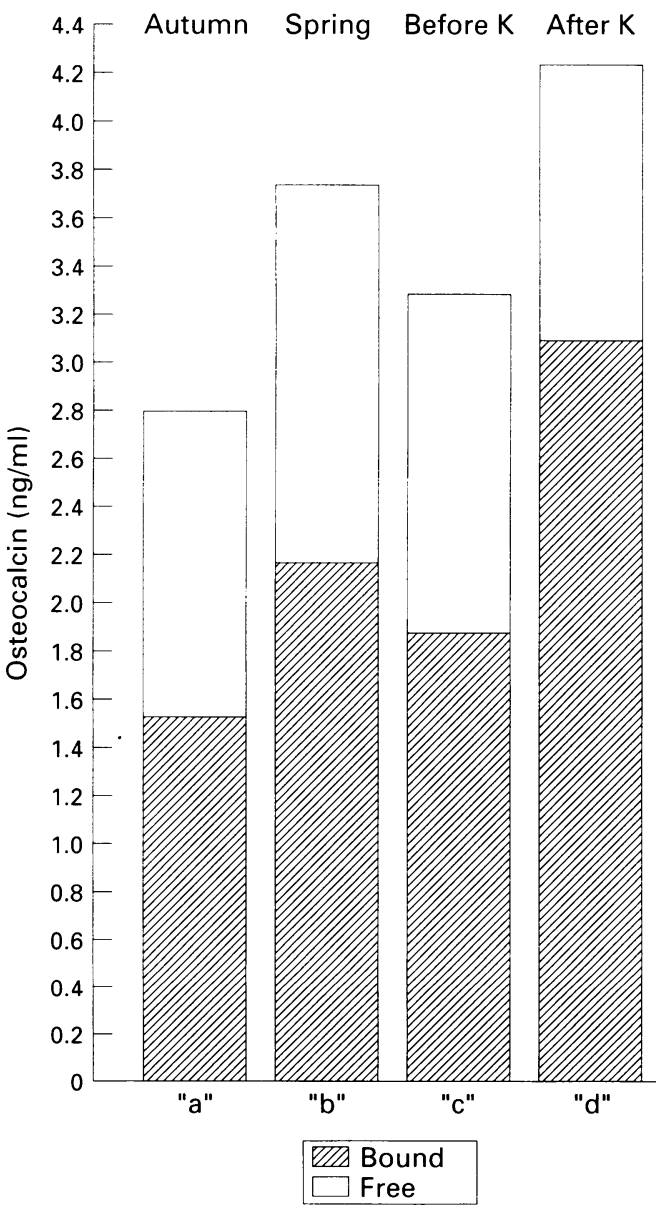

Figure 2 The vertical axis gives osteocalcin "free" or "bound" and on the horizontal axis: "a", 20 samples in autumn (groups I and IIA); " $b$ ", 20 samples in spring (groups I and IID) before supplement or placebo; " $c$ ", 20 samples before vitamin $K$ supplementation (10 samples in autumn (group IA) and 10 samples in spring (group IID)); "d", 20 samples after vitamin $K$ supplementation (10 samples in autumn (group IB) and 10 samples in spring (group II E)). weeks apart as were $\mathrm{B}$ and $\mathrm{E}$, and $\mathrm{C}$ and $\mathrm{F}$. These were the pairs used in the evaluation.

\section{Results}

OSTEOCALCIN (TABLE 1)

In assessment (i) serum osteocalcin values were significantly greater in the spring than in the autumn but the percentages of carboxylation were not significantly different. The same result was present in assessment (ii); similar, but no longer significant, figures were present in assessment (iii).

The values of osteocalcin for assessment (ii) were similar to the results before and after vitamin $\mathrm{K}$ supplementation (fig 2) - that is, the extent of the rise in total osteocalcin in the spring was similar to that after giving vitamin $\mathrm{K}$. However, the two increases were different (fig 2) when examined as "free" (undercarboxylated) osteocalcin or "bound" (carboxylated). In fig 2 the rise in bound osteocalcin was significantly greater after vitamin $\mathrm{K}$ supplementation $(\mathrm{p}<0.001)$, as we reported previously. ${ }^{16}$ In the seasonal rise in osteocalcin there is a similar proportion of "free" compared with "bound" osteocalcin in spring as compared with autumn.

URINARY PYRIDINIUM CROSSLINKS (TABLE 2)

The values for the two pyridinium crosslinks move in opposite directions when compared between autumn and spring. Pyridinoline was lower in the autumn than the spring, whereas deoxypyridinoline was higher in autumn than in spring. The result is that the ratio of pyridinoline:deoxypyridinoline was strikingly different between autumn and spring. Of the 60 pairs, 59 were higher in the spring and the remaining value was equal. This finding was present at a very high level of significance in all three assessments (i), (ii) and (iii).

\section{CALCIUM (TABLE 2)}

There were no differences in urinary calcium measured as $\mathrm{mmol} / \mathrm{mmol}$ creatinine between autumn and spring. The spring value, although higher than the autumn value, was not significantly different.

ALKALINE PHOSPHATASE (TABLE 3; AS CAN BE SEEN IN THIS TABLE THE ASSESSMENTS IN THIS SECTION ARE RENUMBERED (I) (II) (IIIX AND Y) FOR REASONS GIVEN BELOW)

In assessment (i) $(\mathrm{A}+\mathrm{B}+\mathrm{C}$ cf $\mathrm{D}+\mathrm{E}+$ F) total ALP was raised in the autumn com- 
Table 2 Urinary pyridinium crosslinks

\begin{tabular}{|c|c|c|c|c|c|c|c|}
\hline $\begin{array}{l}\text { Pyrinium } \\
\text { crosslinks } \\
\text { (nmol/mmol } \\
\text { creatinine) }\end{array}$ & Assessment* & Autumn & $S D$ & Spring & $S D$ & $\begin{array}{l}\text { Paired } \\
t \text { test }\end{array}$ & $p$ value \\
\hline \multicolumn{8}{|l|}{ Pyridinoline } \\
\hline (60 pairs) & (i) & $62 \cdot 47$ & $16 \cdot 12$ & $71 \cdot 07$ & $15 \cdot 55$ & $t=4 \cdot 29$ & $\mathrm{p}<0.001$ \\
\hline (20 pairs) & (ii) & $64 \cdot 06$ & $18 \cdot 84$ & $70 \cdot 38$ & $17 \cdot 53$ & $t=1.39$ & NS \\
\hline (10 pairs) & (iii) & $67 \cdot 77$ & $22 \cdot 39$ & $70 \cdot 10$ & $18 \cdot 08$ & $t=0.33$ & NS \\
\hline \multicolumn{8}{|c|}{ Deoxypyridinoline } \\
\hline (60 pairs) & (i) & $22 \cdot 38$ & $7 \cdot 20$ & $19 \cdot 12$ & $5 \cdot 86$ & $t=4 \cdot 25$ & $\mathrm{p}<0.001$ \\
\hline (20 pairs) & (ii) & $22 \cdot 67$ & $8 \cdot 12$ & $19 \cdot 43$ & $6 \cdot 83$ & $t=2 \cdot 11$ & $\mathrm{p}<0.05$ \\
\hline (10 pairs) & (iii) & $21 \cdot 01$ & $11 \cdot 75$ & $17 \cdot 78$ & $9 \cdot 25$ & $t=1 \cdot 31$ & NS \\
\hline \multicolumn{8}{|c|}{ Pyridinoline:deoxypyridinoline ratio } \\
\hline (60 pairs) & (i) & $2 \cdot 86$ & 0.40 & $3 \cdot 84$ & 0.58 & $t=15 \cdot 25$ & $\mathrm{p}<0.001$ \\
\hline (20 pairs) & (ii) & $2 \cdot 87$ & 0.49 & $3 \cdot 76$ & 0.56 & $t=7.69$ & $\mathrm{p}<0.001$ \\
\hline (10 pairs) & (iii) & 2.99 & 0.63 & $3 \cdot 71$ & $0 \cdot 44$ & $t=5 \cdot 16$ & $\mathrm{p}<0.001$ \\
\hline \multicolumn{8}{|c|}{ Urinary calcium ( $\mathrm{mmol} / \mathrm{mmol}$ creatinine) } \\
\hline (60 pairs) & (i) & 0.49 & $0 \cdot 26$ & 0.53 & 0.34 & $t=1 \cdot 0$ & NS \\
\hline (20 pairs) & (ii) & 0.48 & 0.32 & 0.47 & 0.39 & $\mathrm{t}=0.2$ & NS \\
\hline (10 pairs) & (iii) & 0.44 & $0 \cdot 22$ & 0.44 & $0 \cdot 20$ & $t=0.02$ & NS \\
\hline
\end{tabular}

* See Methods.

Table 3 Total, bone plus liver, bone, and liver alkaline phosphatase activities

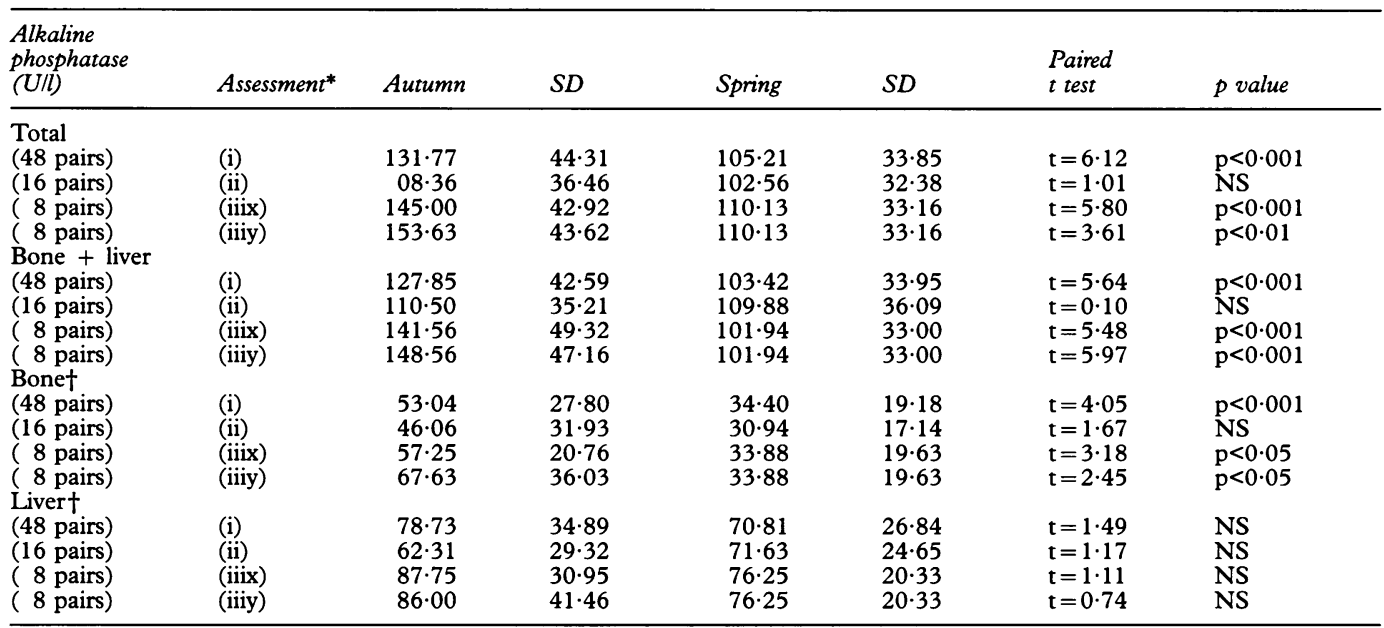

* See Methods: 48 pairs = A + B + C cf D +E + F (groups I and II); 16 pairs = A cf D (groups I and II); 8 pairs $x=B$ cf D (group II); 8 pairs $\mathrm{y}=\mathrm{C}$ cf $\mathrm{D}$ (group II). $†$ The subtraction is made deliberately from the total (see text).

pared with spring. This is mainly due to the $B$ and $\mathrm{C}$ autumn samples having significantly higher bone ALP activities. The figure for liver ALP was greater in autumn than in spring, but this was not significant. None of the patients had raised ALP activities from intestinal or other sources. The differences between measurement of total compared with bone plus liver are very small; the mean difference in autumn is $3.92 \mathrm{U} / 1$ and in spring is $1.79 \mathrm{U} / 1$, these activities not being significantly different. In assessment (ii) (table $3 \mathrm{~A} \mathrm{cf} \mathrm{D)} \mathrm{there} \mathrm{was}$ no difference and the autumn rise in assessment (i) was due to rises later in autumn in samples $\mathrm{B}$ and $\mathrm{C}$. In assessment (iiix and $\mathrm{y}$ ) the $\mathrm{B}$ and $\mathrm{C}$ rises in group II in autumn were compared with group II D and they were significantly greater for bone or bone plus liver ALP.

\section{Discussion}

The seasonal changes in osteocalcin, pyridinium crosslinks and ALP were incidental findings in a study of vitamin supplementation in post-menopausal osteoporotic women who had sustained a Colles fracture two to three years before.

The seasonality of serum concentrations of 25 hydroxyvitamin D3 $(25(\mathrm{OH}) \mathrm{D})$ has been studied extensively. ${ }^{22-27}$ In the Northern hemisphere, this has a peak in July and a nadir in
January. In the young the concentration of the active D3 metabolite calcitriol $\left(1,25(\mathrm{OH})^{2} \mathrm{D}\right)$ does not become deficient in winter, as it has been reported to do in the elderly. ${ }^{23}$ There is an extensive literature showing that parathyroid hormone (PTH) is seasonally high when the serum concentration of $25(\mathrm{OH}) \mathrm{D} 3$ is low. ${ }^{24-26}$ Krall et $a l^{27}$ also confirmed the inverse relation between serum $25(\mathrm{OH}) \mathrm{D}$ concentrations and PTH, concluding that intakes over $220 \mathrm{IU}$ of vitamin $\mathrm{D}$ per day may be sufficient to keep 25(OH)D concentrations constant, thus preventing a seasonal rise in the PTH concentration with its associated risk to the skeleton. It is likely that sunlight is a "time setter" for bone remodelling and there is increasing evidence that BMD varies by season. $^{28-30}$ Vitamin $\mathrm{D}$ status and PTH concentration may well be key factors in the observed changes, but such biochemical changes, which are well documented in the literature, were not studied here. In the study by Bergstralh et $a l^{28}$ the average BMD of the lumbar spine was $1.4 \%$ higher in the late summer than in the winter months. There are other reports supporting this finding. Krølner ${ }^{30}$ found BMD greatest in mid-August. It may be that the balance of bone remodelling in autumn/ winter is in favour of bone resorption whereas in spring/summer it is in favour of bone formation. 
In our study serum osteocalcin concentrations in spring were about one third greater compared with the autumn values. There is a definitive paper by Thomsen et $a l^{11}$ who measured osteocalcin monthly in 15 normal young individuals aged 27-39 years and found a zenith in February and a nadir in summer, the size of the seasonal variation being $23 \%$ : the osteocalcin values were highest when the vitamin $\mathrm{D}$ level would be expected to be lowest. The findings in the present study are consistent with those. ${ }^{11}$ Our spring timing is just past their peak and our autumn timing is only two to three months beyond the nadir.

Vitamin D controls the synthesis of osteocalcin in vitro in cultures of osteosarcoma cells. ${ }^{31}$ As in the present study the percentage of undercarboxylation was found to be similar in autumn and spring by Szulc et al ${ }^{15}$ : however, in that study Szulc et al made monthly readings and the level of undercarboxylation was greater in winter than summer and raised by vitamin $\mathrm{D}$ and calcium. The mean value of osteocalcin rises by $0.93 \mathrm{ng} / \mathrm{ml}$ in spring compared with autumn and it is $0.95 \mathrm{ng} / \mathrm{ml}$ greater after vitamin $\mathrm{K}$ supplementation than before. These two increases are dissimilar because the seasonal rise is due to an increase in both free and bound osteocalcin while the mean values for per cent carboxylation were similar in autumn and spring. In the rise after vitamin $K$ the free level falls and the bound level increases, so that the rise in total osteocalcin is due entirely to the bound value (fig 2 ).

Urinary pyridinium crosslinks provide a measure of bone resorption with distinct advantages in terms of sensitivity and specificity over urinary hydroxyproline. Pyridinium crosslinks are formed during maturation of collagen fibres and are released during the breakdown of bone, providing a measure of bone resorption. ${ }^{1}$ The values of pyridinoline and deoxypyridinoline have been previously reported to be highly correlated, ${ }^{1}$ but they move in opposite directions when examined by season. There is already known to be a circadian rhythm, the value being highest usually at night. ${ }^{6}$ The changes in the pyridinoline:deoxypyridinoline ratio are difficult to interpret but undoubtedly the observed differences may be an important consideration in the design and interpretation of future studies. The changes in this ratio are unlikely to be the result of degradation of collagen in tissues other than bone. ${ }^{5632}$ The amount of deoxypyridinoline formed will depend on the degree of hydroxylation of the specific lysine residues in the collagen helix that are involved in crosslinking. This is therefore controlled intracellularly during the synthesis of bone collagen by the activity of lysyl hydroxylase. As calcium ions are known to inhibit this enzyme, ${ }^{33}$ it is conceivable that slight seasonal differences in ionised calcium concentrations in bone might contribute to changes in the crosslink ratio. This may also be associated with the changes in the calciotropic hormones discussed previously. However, the unknown time-lag between synthesis of collagen and its degradation as mature bone matrix is an additional factor confounding the interpretation of these observations.

Total ALP activities were higher in the autumn and lower in the spring. During the six weeks of the autumn study the activities rose significantly between late November and early January. This confirms the 1947 study by Tuba et $a l^{34}$ and a subsequent study in 1981 from Dundee. ${ }^{35}$ Bone ALP activity was also significantly different and was the major contributor to the seasonality of total ALP activities. This seems to be consistent with an association with the calciotropic hormones, vitamin D, PTH, and calcitonin. Surprisingly, the changes in serum ALP activities were in the opposite direction to those for osteocalcin when autumn was compared with spring.

These studies were made at only two points in the year (late autumn and early spring), approximately three months apart. The examination of the results in the three different assessments suggests that the changes reported are due to season and should not be attributed to vitamin supplementation.

We are grateful to Miss Helen Arnold for her contribution to this work. Mrs Alison Stewart was responsible for bone ultrasound measurements. The co-operation of the 20 women enrolled into the study is recognised. Access to patients was given by surgeons in the accident and emergency and orthopaedic by surgeons in the accident and emergency and orthopaedic departments. The manuscript was typed by Mrs Muriel Burnett. One of us (ASD) held a Leverhulme Research Fellowship.
Financial support and other help was provided by Boehringer Financial support and other help was provided by Boehringer porosis Trust. DMR is grateful to the Arthritis and Rheumatism Council for continued support.

1 Anonymous. Pydridinium crosslinks as markers of bone resorption (editorial). Lancet 1992;340:278-9.

2 Eyre DR New markers of bone resorption (editorial). $f$ Clin Endocrinol Metab 1992;74:470A-C.

3 Delmas PD. Clinical use of biochemical markers of bone remodelling in osteoporosis. Bone 1992;13(Suppl 1):S1721 .

4 Delmas PD, Schlemmer A, Gineyts E, Riis B, Christiansen C. Urinary excretion of pyridinoline crosslinks correlates with bone turnover measured on iliac crest biopsy in patients with vertebral osteoporosis. $\mathcal{F}$ Bone Miner Res 1991;6:639-44.

5 Robins S, Black D, Paterson C, Reid D, Duncan A, Seibel $M$. Evaluation of urinary hydroxypyridinium crosslink measurements as resorption markers in metabolic bone measurements as resorption markers in me

6 Seibel W, Robins SP, Bilezikian JP. Urinary pyridinium crosslinks of collagen: specific markers of bone resorption in metabolic bone disease. Trends Endocrinol Metab 1992; 3:263-70.

7 Delmas PD. Biochemical markers of bone turnover: methodology and clinical use in osteoporosis. $\mathrm{Am} \mathcal{F} \mathrm{Med}$ 1991;91(Suppl 5B):59S-63S

8 Schlemmer A, Hassager C, Jensen SB, Christiansen C. Marked diurnal variation in urinary excretion of pyridinium cross-links in premenopausal women. $f$ Clin Endocrinol Metab 1992;74:476-80.

9 Eastell R, Calvo MS, Burritt MF, Offord KP, Russell RG, Riggs BL. Abnormalities in circadian patterns of bone resorption and renal calcium conservation in type I osresorption and renal calcium conservation in type I
teoporosis. $₹$ Clin Endocrinol Metab 1992;74:487-94.

10 McLaren AM, Isdale AH, Whiting PH, Bird HA, Robins SP. Physiological variations in the urinary excretion of pyridinium crosslinks of collagen. $\mathrm{Br} \mathcal{F}$ Rheumatol 1993; 32:307-12.

11 Thomsen K, Eriksen EF, Jorgensen JCR, Charles P, Mosekilde L. Seasonal variation of serum bone GLA protein. Scand f Clin Lab Invest 1989;49:605-11.

12 Price PA, Williamson MK, Lothringer JW. Origin of the vitamin $\mathrm{K}$-dependent bone protein found in plasma and its clearance by kidney and bone. $\mathcal{F}$ Biol Chem 1981;246: $12760-6$.

13 Knapen MHJ, Hamulyak K, Vermeer C. The effect of vitamin $\mathrm{K}$ supplementation on circulating osteocalcin (bone gla protein) and urinary calcium excretion. $A n n$ Inter Med 1989;111:1001-5.

14 Merle B, Delmas PD. Normal carboxylation of circulating osteocalcin (bone gla protein) in Paget's disease of bone. osteocalcin (bone gla protein)
Bone Miner 1990;11:237-45.

15 Szulc P, Chapuy M-C, Meunier PJ, Delmas PD. Serum undercarboxylated osteocalcin is a marker of risk of hip undercarboxylated osteocalcin is a marker of risk of hip

16 Douglas AS, Robins SP, Hutchison JD, Porter RW, Stewart A, Reid DM. Carboxylation of osteocalcin in post- 
menopausal osteoporotic women following Vitamin $\mathrm{K}$ and D supplementation. Bone 1995;17:15-20.

17 Knapen MHJ, Jie K-SGJ, Hamulyak K, Vermeer C. Vitamin $\mathrm{K}$-induced changes in markers for osteablast activity and urinary calcium loss. Calcif Tissue Int 1993;53:81-5.

18 Pratt DA, Daniloff Y, Duncan A, Robins SP. Automated analysis of the pyridinium crosslinks of collagen in tissue and urine using solid-phase extraction and reversed-phase high-performance liquid chromatography. Anal Biochem 1992;207:168-75.

19 Statland BE, Nishi HH, Young DS. Serum alkaline phosphatase: total activity and isoenzyme determinations made by use of

20 Naik RB, Gosling P, Price CP. Comparative study of alkaline phosphatase isoenzymes, bone histology and skeletal radiography in dialysis bone disease. BMF 1977;i:130710.

21 Price CP. Multiple forms of human serum alkaline phosphatase: detection and quantitation. Ann Clin Biochem 1993;30:355-72.

22 Stamp TCB, Round JM. Seasonal changes in human plasma levels of 25-hydroxyvitamin D. Nature 1974;247:563-5.

23 Bouilion RA, Auwerx JH, Lissens WD, Pelemans WK. Vitamin D status in the elderly; seasonal substrate deficiency causes 1,25-dihydroxy cholecalciferol deficiency. ficiency causes 1,25-dihydroxy

24 Meller Y, Restenbaum RS, Galinsky D, Shany S. Seasonal variation in serum levels of vitamin $D$ metabolises and parathormone in geriatric patients with fractures in southern Israel. Is f Med Sci 1986;22:8-11.

25 Lips P, Hackeng WHL, Jongen MJM, Ginkel FC van, Netelenbos JC. Seasonal variation in serum concentration of parathyroid hormone in elderly people. 7 Clin Endocrino Metab 1983;57:204-6.
26 Enorring JV, Slatis P, Weber TH, Helenuis T. Serum levels of 25 hydroxyvitamin D, 24,25-dihydroxyvitamin D and parathyroid hormone in patients with femoral neck fracture in Southern Finland. Clin Endocrinol 1982;17:189-94.

27 Krall EA, Sahyoun N, Tannenbaum S, Dallal GE, DawsonHughes $B$. Effect of vitamin D intake on seasonal variations in parathyroid hormone secretion in postmenopausal women. N Engl f Med 1989;32:1777-83.

28 Bergstralh EJ, Sinaki M, Offord KP, Wahner HW, Melton LJ. Effect of season on physical activity score, back extensor Effect of season on physical activity score, back extensor
muscle strength and lumbar bone mineral density. f Bone muscle strength and lumbar
Miner Res 1990;5:371-7.

29 Riggs BL, Wahner HW, Dunn WL, Mazess RB, Offord RP, Melton LJ. Differential changes in bone mineral density of the appendicular and axial skeleton with ageing. $f \mathrm{Clin}$ Invest 1981;67:328-35.

$30 \mathrm{Krølner}$ B. Seasonal variation of lumbar spine bone mineral content in normal women. Calif Tissue Int 1983;35:114-18.

31 Price PA, Baukol BE. 1,25(OH)2D3 increases the synthesis of the vitamin $\mathrm{K}$ dependent bone protein by osteosarcoma of the vitamin K dependent bone pro

32 Eyre DR, Koob TJ van, Ness RP. Quantitation of hydroxypyridinium crosslinks in collagen by high-performance liquid chromatography. Anal Biochem 1984;137:1380-8.

33 Ryhanen L. Lysyl hydroxylase. Further purification and characterization of the enzyme from chick embryos and chick embryo cartilage. Biochim Biophys Acta 1976;438: $71-89$.

34 Tuba J, Cantor MM, Siemens H. Phosphatases and inorganic phosphorus in normal human serum. $7 \mathrm{Lab}$ Clin organic phosphorus
Med 1947;32:194-5.

35 Devgun MS, Paterson CR, Martin BT. Seasonal changes in the activity of serum alkaline phosphatase. Enzyme 1981;26:301-5. 